\title{
Potássio lixiviado da palha de aveia-preta e milheto após a dessecação química
}

\author{
Ciro Antonio Rosolem ${ }^{(1)}$, Juliano Carlos Calonego ${ }^{(1)}$, José Salvador Simoneti Foloni(2) e Rodrigo Arroyo Garcia ${ }^{(1)}$
}

(1)Universidade Estadual Paulista, Fac. de Ciências Agronômicas, Dep. de Produção Vegetal, Caixa Postal 237, CEP $18603-970$ Botucatu, SP. E-mail: rosolem@fca.unesp.br, jcalonego@fca.unesp.br, ragarcia@fca.unesp.br (2)Universidade do Oeste Paulista, Dep. de Fitotecnia, Rod. Raposo Tavares, Km 572, CEP 19067-175 Presidente Prudente, SP. E-mail: sfoloni@unoeste.br

Resumo - O objetivo deste trabalho foi avaliar a lixiviação de K da palha de aveia-preta (Avena strigosa) e de milheto (Pennisetum glaucum), utilizando-se chuva simulada em diferentes períodos após a dessecação química. As plantas foram cultivadas em vasos, e aos 50 dias da emergência foram manejadas com herbicida e submetidas à chuva simulada de 5 e 10 mm, aos 3, 6, 9, 12 e 15 dias após a dessecação (DAD). A quantidade de K lixiviado das palhas, considerando uma quantidade de palha equivalente a $8,0 \mathrm{t} \mathrm{ha}^{-1}$ de matéria seca, aumentou à medida que o estado de senescência das plantas evoluiu após a dessecação. Com a aplicação de $10 \mathrm{~mm}$ de chuva aos $15 \mathrm{DAD}$, a palha de aveia-preta disponibilizou, aproximadamente, $11,1 \mathrm{~kg} \mathrm{ha}^{-1} \mathrm{de} \mathrm{K}$. A água da chuva extrai maior quantidade de $\mathrm{K}$ da palha de aveia-preta em relação à palha de milheto, tanto com a lâmina de 5 mm como de $10 \mathrm{~mm}$, e essas diferenças são maiores de acordo com o estado avançado de desidratação do material vegetal.

Termos para indexação: Avena strigosa, Pennisetum americanum, ciclagem de nutrientes, plantas de cobertura, plantio direto.

\section{Potassium leaching from black oat and pearl millet straw after chemical desiccation}

\begin{abstract}
Potassium leaching from black oat (Avena strigosa) and pearl millet (Pennisetum glaucum) straw as affected by simulated rainfall at different moments after chemical desiccation was evaluated. Cover crops were grown in pots, in Botucatu, State of São Paulo, Brazil. Fifty days after emergence, plants were sprayed with herbicide. Three, 6, 9 and 15 days after the desiccation the straw received simulated rains corresponding to 5 and $10 \mathrm{~mm}$, considering a mulch of $8 \mathrm{tha}^{-1}$. The amount of $\mathrm{K}$ leached from plant residues increased after the desiccation. Fifteen days after the desiccation, a rainfall of $10 \mathrm{~mm}$ leached $11.1 \mathrm{~kg} \mathrm{ha}^{-1} \mathrm{of} \mathrm{K}$. The higher potential of black oat straw to leach $\mathrm{K}$ was observed with $10 \mathrm{~mm}$ of rain. The amount of $\mathrm{K}$ released by rains from black oat straw is greater from the pearl millet with 5 and $10 \mathrm{~mm}$, and this difference increases according to the loss of water of the tissues.
\end{abstract}

Index terms: Avena strigosa, Pennisetum americanum, nutrient cycling, cover crops, no-till.

\section{Introdução}

O cultivo de espécies vegetais como plantas de cobertura pode aumentar a oferta de nutrientes nas camadas superficiais do solo (Fiorin, 1999). O K contido na palha da superfície do solo em sistemas de semeadura direta pode contribuir para nutrir a cultura sucessora (Foloni \& Rosolem, 2004; Rosolem et al., 2006a).

O manejo químico de espécies de cobertura do solo com herbicida não-seletivo de ação sistêmica, como o glifosato, provoca a morte lenta das plantas, o que atrasa o processo de decomposição da palha (Ahrens, 1994). Dessa forma, a oferta de nutrientes dos restos vegetais de plantas mortas por herbicidas, e mantidas em pé, tende a ser menos intensa, em razão da menor taxa de decomposição biológica.

Por sua vez, a ação da água das chuvas, independentemente da mineralização da matéria orgânica, pode constituir um fator importante na lixiviação de nutrientes de restos vegetais, como ocorre com o K. Nos trabalhos de Silva \& Ritchey (1982) e Klepker \& Anghinoni (1995), constatou-se aumento dos teores de $\mathrm{K}$ do solo próximo à base dos caules das plantas de milho devido à lavagem do nutriente da parte aérea senescente no final do ciclo da cultura. Rosolem et al. (2006a) também observaram incremento no teor de K trocável no solo, até $4 \mathrm{~cm}$ de profundidade, após a simulação de $30 \mathrm{~mm}$ de chuva sobre a palha de milheto. 
Da mesma forma, Rosolem et al. (2006b) constataram aumento no teor de $\mathrm{K}$ até $8 \mathrm{~cm}$ de profundidade, com $50 \mathrm{~mm}$ de chuva sobre a palha de milheto, ou seja, não constituindo perdas do nutriente por lixiviação no perfil do solo.

O K não é metabolizado na planta e forma ligações com moléculas orgânicas de fácil reversibilidade. Além disso, é o íon mais abundante nas células vegetais (Marschner, 1995). A extração relativamente fácil de $\mathrm{K}$ do tecido vegetal foi descrita por Moraes \& Arens (1969), que constataram que o nutriente sofreu lixiviação considerável das folhas de plantas cultivadas, quando foram imersas em água destilada, mostrando que este fenômeno pode ocorrer em condições de campo em virtude da ação da água do orvalho ou das chuvas.

Portanto, as palhas das plantas de cobertura podem constituir uma fonte adicional de K que, pela ação da água das chuvas, pode proporcionar aumento do teor do nutriente no solo. Contudo, o estádio de senescência das plantas, após serem submetidas ao herbicida, pode comprometer o sincronismo entre a fonte do nutriente (palha da superfície do solo) e a demanda da cultura subseqüente em sistemas com semeadura direta. Rosolem et al. (2003) submeteram restos vegetais de seis espécies de plantas de cobertura a diferentes quantidades de chuva aplicada e observaram lixiviação de $\mathrm{K}$, com valores que variaram de 7 a $24 \mathrm{~kg} \mathrm{ha}^{-1} \mathrm{de} \mathrm{K}$, sem que houvesse decomposição da palha.

Estudos sobre a ciclagem e o processo de disponibilização de $\mathrm{K}$ da palha de plantas de cobertura são importantes para subsidiar discussões sobre o manejo da adubação potássica em cultivos com semeadura direta.

O objetivo deste trabalho foi quantificar a lixiviação de $\mathrm{K}$ da palha de espécies vegetais utilizadas como plantas para cobertura do solo, com a simulação de chuva em diferentes estádios de senescência após a aplicação de herbicida.

\section{Material e Métodos}

O experimento foi conduzido em casa de vegetação da Faculdade de Ciências Agronômicas, Unesp, em Botucatu, SP. Utilizou-se um solo classificado como Latossolo Vermelho distroférrico (Embrapa, 1999) de textura média (630 $\mathrm{g} \mathrm{kg}^{-1}$ de areia, $40 \mathrm{~g} \mathrm{~kg}^{-1}$ de silte e $330 \mathrm{~g} \mathrm{~kg}^{-1}$ de argila). $\mathrm{O}$ solo foi secado ao ar e passado em peneira com malha de $2 \mathrm{~mm}$. A análise química (Raij et al., 2001) revelou os seguintes valores: $\mathrm{pH}\left(\mathrm{CaCl}_{2}\right.$,
$0,01 \mathrm{M}) 4,1 ; 1,0 \mathrm{mg} \mathrm{dm}^{-3} \mathrm{de} \mathrm{P}_{\text {resina }} ; 18,0 \mathrm{~g} \mathrm{dm}^{-3} \mathrm{de} \mathrm{MO}$; $75,0 \mathrm{mmol}_{\mathrm{c}} \mathrm{dm}^{-3}$ de $\mathrm{H}+\mathrm{Al} ; 0,1 \mathrm{mmol}_{\mathrm{c}} \mathrm{dm}^{-3}$ de $\mathrm{K}$; 4,0 $\mathrm{mmol}_{\mathrm{c}} \mathrm{dm}^{-3}$ de $\mathrm{Ca} ; 1,0 \mathrm{mmol}_{\mathrm{c}} \mathrm{dm}^{-3}$ de $\mathrm{Mg}$; $5,1 \mathrm{mmol}_{\mathrm{c}} \mathrm{dm}^{-3} \mathrm{de} \mathrm{SB} ; 81,1 \mathrm{mmol}_{\mathrm{c}} \mathrm{dm}^{-3}$ de CTC e 6,3\% de saturação por bases $(\mathrm{V})$. O teor de água do solo na capacidade de campo, tensão de -0,01 MPa no aparelho extrator de Richards, determinado conforme Embrapa (1997), foi de $160 \mathrm{~g} \mathrm{~kg}^{-1}$.

Aplicou-se calcário dolomítico (CaO: 28\%, MgO: $20 \%$ e PRNT: 95\%) para elevar a saturação por bases a $70 \%$ (Raij et al., 1996). A terra foi umedecida até atingir a capacidade de campo e acondicionada em sacos de plástico por 30 dias. Em seguida, foi secada ao ar e adubada com $100 \mathrm{mg} \mathrm{dm}^{-3}$ de $\mathrm{N}$ (uréia), $200 \mathrm{mg} \mathrm{dm}^{-3}$ de $\mathrm{P}$ (superfosfato simples) e $150 \mathrm{mg} \mathrm{dm}^{-3}$ de $\mathrm{K}$ (cloreto de potássio).

A terra fertilizada foi acomodada em vasos com as seguintes dimensões: $0,25 \mathrm{~m}$ diâmetro e $0,25 \mathrm{~m}$ de profundidade. Foram cultivados milheto (Pennisetum glaucum, var. BN-2) e aveia-preta (Avena strigosa), utilizando sementes pré-germinadas, para minimizar as variações de tempo de emergência existentes entre as espécies. Após a emergência das plântulas, realizou-se um desbaste, deixando-se 30 plantas por vaso. A temperatura da casa de vegetação foi mantida entre 20 e $25^{\circ} \mathrm{C}$ durante todo o experimento, e a umidade relativa do ar entre 70 e $90 \%$. O teor de água nos vasos foi corrigido diariamente para manter a umidade do solo a $80 \%$ da capacidade de campo.

Do $20^{\circ}$ ao $25^{\circ}$ dia após a emergência das plântulas, foram realizadas adubações suplementares nos vasos por meio da água de irrigação, com macro e micronutrientes, totalizando $100,50,50,25,25$ e $53,3 \mathrm{mg} \mathrm{dm}^{-3}$ de N, P, K, Ca, Mg e S, respectivamente, com os sais $\mathrm{NH}_{4} \mathrm{NO}_{3}, \mathrm{NH}_{4} \mathrm{H}_{2} \mathrm{PO}_{4}, \mathrm{KNO}_{3}, \mathrm{CaSO}_{4} \mathrm{e}$ $\mathrm{MgSO}_{4}$. Os micronutrientes adicionados foram $\mathrm{B}, \mathrm{Zn}$, $\mathrm{Mo}$, Mn e Cu na dose de $1 \mathrm{mg} \mathrm{dm}^{-3}$, pelas fontes $\mathrm{H}_{3} \mathrm{BO}_{3}$, $\mathrm{ZnCl}_{2}, \mathrm{H}_{2} \mathrm{MoO}_{4}, \mathrm{MnCl}_{2}$ e $\mathrm{CuCl}_{2}$.

Aos 50 dias depois da emergência, as plantas de milheto foram dessecadas com glifosato (i.a.) em dose equivalente a $2,4 \mathrm{~kg} \mathrm{ha}^{-1}$. A pulverização foi realizada com equipamento manual pressurizado com $\mathrm{CO}_{2}$, operando à pressão constante de $150 \mathrm{kPa}$, munido de barra de aplicação com quatro bicos de jato plano, do tipo leque, modelo 110.04, espaçados em 0,40 m, que proporcionaram um volume de calda equivalente a $40 \mathrm{~mL} \mathrm{~m}^{-2}$. A altura da barra foi mantida a $1,20 \mathrm{~m}$ do solo e a velocidade média de deslocamento durante a pulverização do herbicida foi de $1,0 \mathrm{~m} \mathrm{~s}^{-1}$. 
Após a dessecação das plantas, os vasos foram novamente colocados em casa de vegetação, e aos 3,6 , 9, 12 e 15 dias após essa operação, processou-se o corte das plantas na altura do colo. As plantas foram picadas em pedaços entre 3 e $5 \mathrm{~cm}$ de comprimento para serem submetidas à lavagem pelo simulador de chuvas. Como o procedimento do trabalho foi de simular chuvas aos 3 , $6,9,12$ e 15 dias após a dessecação (DAD) das plantas, os restos vegetais apresentavam-se em diferentes estádios de senescência, e conseqüentemente, com teor de água decrescente ao longo do tempo. Assim, foi necessário, um dia antes de cada época de aplicação de chuva, coletar amostras das plantas e desidratá-las em estufa de aeração forçada por 24 horas com temperatura regulada a $60^{\circ} \mathrm{C}$, a fim de aferir a quantidade de palha a ser utilizada no processo de simulação, equivalente a uma cobertura do solo de $8 \mathrm{t} \mathrm{ha}^{-1}$ de matéria vegetal, secada a $60^{\circ} \mathrm{C}$. Parte dessas amostras, antes de serem submetidas à simulação de chuva, foi reservada para determinação dos teores de K segundo método descrito por Malavolta et al. (1997).

O simulador de chuvas utilizado no experimento foi descrito detalhadamente por Silva (2000). Foi utilizada a barra de suporte dos bicos de alta vazão Spray System, modelo TK-SS-20, com o espaço entre bicos de 0,50 m. $\mathrm{O}$ equipamento foi calibrado para aplicar um volume de água equivalente a $2,5 \mathrm{~mm}$ a cada passagem, operando à pressão de trabalho de $81 \mathrm{~Pa}$, com velocidade de deslocamento da barra de $0,0925 \mathrm{~m} \mathrm{~s}^{-1}$. Para que fossem aplicadas quantidades de chuva equivalentes a 5 e $10 \mathrm{~mm}$, foi necessário executar dois e quatro deslocamentos da barra de pulverização, respectivamente.

Para receber a água da chuva simulada, as palhas foram colocadas em anéis de PVC rígido com área superficial de $0,049 \mathrm{~m}^{2}$, altura de $0,10 \mathrm{~m}$ e telados ao fundo com fios de nylon com malha de $10 \mathrm{~mm}$. Cada anel recebeu 39,27 g de palha seca, equivalente a $8 \mathrm{t} \mathrm{ha}^{-1}$ de massa de matéria seca vegetal, ajustados de acordo com o teor de umidade remanescente de cada material em cada período após a dessecação. Os anéis foram fixados em funis de plástico, e a água, após passar pelas palhas, foi coletada em recipientes protegidos por cortina de plástico. As estruturas que continham as palhas foram colocadas em pontos eqüidistantes ao longo do percurso de deslocamento da barra. As palhas de cada espécie avaliada, de acordo com o delineamento experimental adotado, foram colocadas em quatro anéis distribuídos em blocos. Foram colocados também quatro anéis sem palha em todas as aplicações de chuva para determinação do $\mathrm{K}$ da água utilizada na simulação. $\mathrm{O}$ procedimento adotado foi baseado em método desenvolvido por Maciel (2001) e em testes preliminares.

Ao final de cada aplicação de chuva, o volume da água que passou pelas palhas foi determinado. A seguir a água foi filtrada e mantida sob refrigeração a $2^{\circ} \mathrm{C}$. Determinou-se também a massa das palhas umedecidas, imediatamente após cada processo de simulação de chuva. Com as massas das palhas secas e úmidas, foi possível calcular a quantidade de água retida, que foi transformada em milímetros, considerando-se a área do anel. As concentrações de K da água percolada foram determinadas em ICP ("Inductively Coupled Plasma"), e os valores foram convertidos para $\mathrm{kg} \mathrm{ha}^{-1}$.

O delineamento experimental utilizado foi o de blocos ao acaso, em um esquema fatorial $(2 \times 2 \times 5)$, sendo constituído das palhas de duas espécies vegetais, milheto e aveia-preta, cultivadas em quatro repetições, submetidas a chuva simulada de 5 e $10 \mathrm{~mm}$, em cinco épocas após o manejo (3, 6, 9, 12 e 15 dias). O estudo estatístico constou de análise de regressão e ajuste de equações matemáticas para expressar adequadamente o comportamento dos resultados obtidos. A fim de ajustar os dados obtidos de água retida na palha e de lixiviação de K da palha, utilizou-se o modelo de Mitscherlich, recomendado para conjuntos de dados em que os incrementos são decrescentes (Raij et al., 1990), e possuem tendência da variável dependente de estabilizarse em um valor constante.

\section{Resultados e Discussão}

Foram constatadas interações significativas entre espécies vegetais, épocas de simulação de chuva após a dessecação e lâminas de chuva, para os resultados de retenção de água na palha, lixiviação de $\mathrm{K}$ nas diferentes épocas e porcentagem de $\mathrm{K}$ lixiviado em relação ao acumulado no tecido vegetal.

O grau de senescência das plantas de cobertura aumentou no decorrer dos dias após a aplicação do herbicida, e levou as duas espécies a apresentarem estados de desidratação crescentes com o avanço do tempo (Figura 1), o que ocasionou aumento na retenção de água da chuva pelas coberturas (Figura 2). De maneira geral, a palha de aveia-preta reteve mais água que a de milheto, tanto com a simulação de $5 \mathrm{~mm}$ quanto de $10 \mathrm{~mm}$ de chuva, ocorrendo retenção máxima aos 12 DAD; a retenção de água nas palhas de milheto 
apresentou os maiores incrementos até 9 DAD. A lâmina máxima de água retida nas palhas de aveia-preta e milheto foi de aproximadamente $2,3 \mathrm{~mm}$ e $1,5 \mathrm{~mm}$, respectivamente, com a aplicação de $10 \mathrm{~mm}$ de chuva. Esses resultados condizem com os obtidos por Rosolem et al. (2003), que relatam retenção de água semelhante nas palhas de aveia-preta e milheto após simulação de $8 \mathrm{~mm}$ de chuva. Além disso, os autores observaram que, mesmo com a aplicação de $70 \mathrm{~mm}$ de chuva, a retenção de água nas palhas não ultrapassou $3 \mathrm{~mm}$.

As duas espécies estudadas revelaram comportamentos distintos quanto à lixiviação de $\mathrm{K}$ da palha, tanto em função da lâmina de água aplicada, quanto da época de simulação de chuva (Figura 3 ). A quantidade de $\mathrm{K}$ encontrada na água percolada das palhas após $5 \mathrm{~mm}$ de chuva (Figura $3 \mathrm{~A}$ ) foi relativamente pequena, quando comparada com a encontrada após chuva de $10 \mathrm{~mm}$ (Figura $3 \mathrm{~B}$ ), corroborando resultados observados por Rosolem et al. (2003). Isso ocorre, provavelmente, em virtude de a relação entre a quantidade relativa de água retida na palha e a aplicada na forma de chuva ser maior com a lâmina de $5 \mathrm{~mm}$, ou seja, há maior volume de água percolado da palha com a lâmina de $10 \mathrm{~mm}$, levando à maior quantidade de $\mathrm{K}$ extraída, já que o elemento encontra-se, em grande parte, na forma solúvel nas plantas (Malavolta, 1980).

O estado de desidratação das plantas influenciou na lixiviação de $\mathrm{K}$ das palhas de maneira distinta entre as espécies. Verificou-se que tanto a aveia-preta quanto o

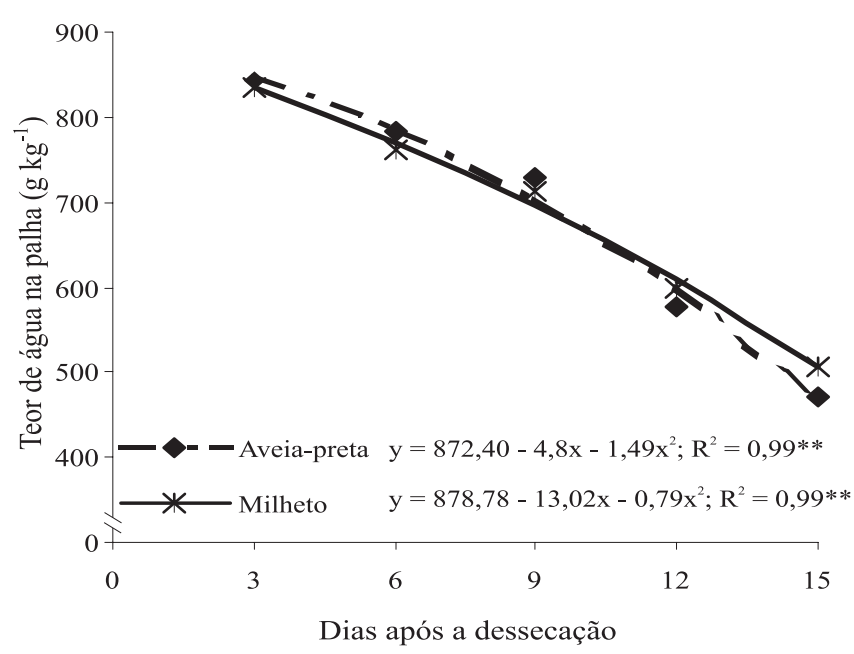

Figura 1. Teor de água na palha da aveia-preta e do milheto em diferentes períodos após a dessecação. **Significativo a $1 \%$ de probabilidade pelo teste $\mathrm{F}$. milheto disponibilizaram menores quantidades desse nutriente em condições em que o tecido vegetal apresentava-se com alto teor de umidade, ou seja, nos primeiros dias após a dessecação. Dessa forma, na medida em que a palha foi perdendo água, a quantidade de K percolada pelas lâminas de chuva aplicadas aumentou. Porém, na aveia-preta, a resposta da quantidade extraída de $\mathrm{K}$ em função do teor de umidade da palha foi crescente até 12 DAD com a chuva de $5 \mathrm{~mm}$, e até $15 \mathrm{DAD}$ com a chuva de $10 \mathrm{~mm}$. Essas lâminas de chuva, ou seja, de 5 e $10 \mathrm{~mm}$, extraíram o equivalente a 2,5 e $11,1 \mathrm{~kg} \mathrm{ha}^{-1} \mathrm{de} \mathrm{K}$, respectivamente, considerando $8 \mathrm{t} \mathrm{ha}^{-1}$ de cobertura morta. Quanto à palha de milheto, a extração de $\mathrm{K}$ foi menor, e foi possível ajustar os dados obtidos seguindo o modelo de Mitscherlich somente com a chuva de $10 \mathrm{~mm}$, cuja extração de $\mathrm{K}$ apresentou os maiores aumentos até $12 \mathrm{DAD}$, atingindo $2,3 \mathrm{~kg} \mathrm{ha}^{-1}$ de $\mathrm{K}$ na água percolada pela palha. No entanto, com a chuva de $5 \mathrm{~mm}$, a extração de $\mathrm{K}$ da palha de milheto não foi alterada pelo estado de desidratação das plantas, havendo lixiviação média de $0,6 \mathrm{~kg} \mathrm{ha}^{-1}$ de $\mathrm{K}$.

A remoção de nutrientes minerais das folhas pela água depende de fatores como cerosidade, molhabilidade e estado da cutícula (Malavolta, 1980). Sendo assim, o aumento na lixiviação de K dos tecidos vegetais, à medida que o estado de senescência das

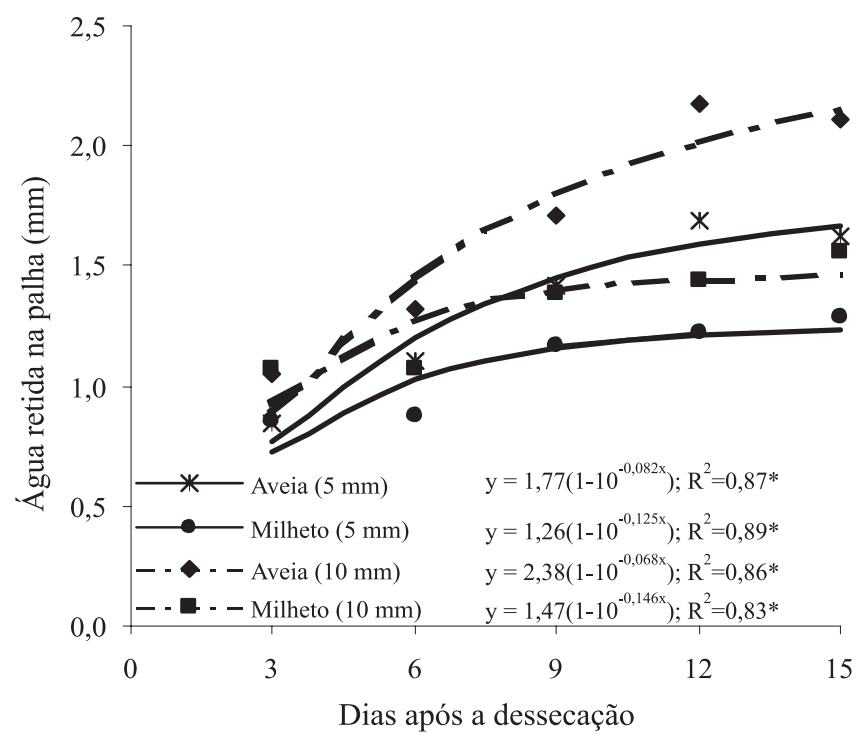

Figura 2. Retenção de água na palha da aveia-preta e do milheto em função das duas lâminas de chuva simuladas em diferentes épocas após a dessecação. *Significativo a 5\% de probabilidade pelo teste $\mathrm{F}$. 
plantas evoluiu, pode ser explicado por uma possível desorganização da cutícula que reveste a epiderme das folhas, que constitui uma barreira à penetração de água. Outra hipótese levantada por Rosolem et al. (2003) é que, quando a palha está seca, há, durante o processo de molhamento, significativa difusão do K dos vacúolos, de modo a intensificar a lavagem do nutriente. Porém, à medida que o grau de hidratação da palha aumenta, ocorre redução no fluxo de saída de líquido dos restos vegetais, ou seja, devido à alta intensidade da chuva durante o processo de simulação, apenas a água que se encontra mais à superfície do tecido vegetal é trocada pela água que está sendo aplicada.
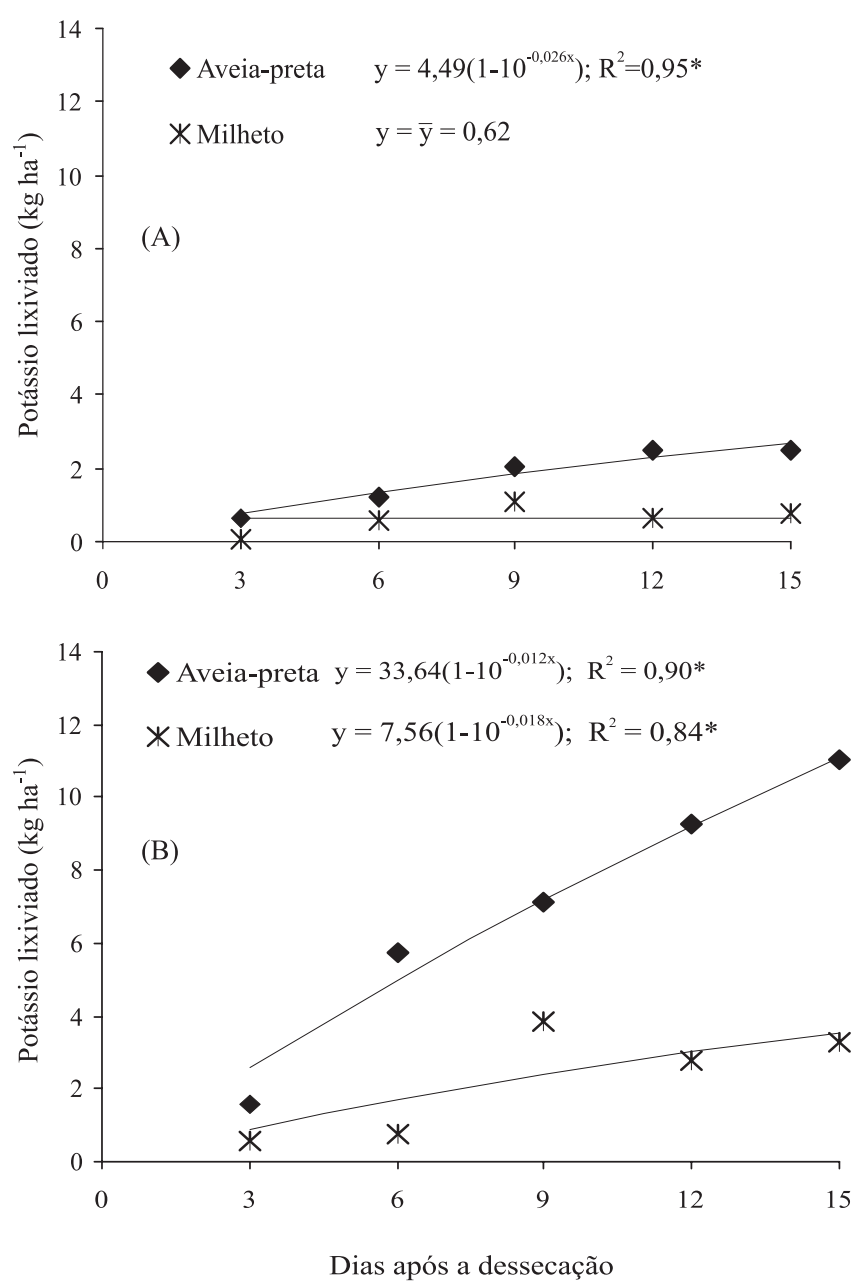

Figura 3. Lixiviação de potássio das palhas da aveia-preta e do milheto em diferentes estádios após a dessecação. A: simulação de $5 \mathrm{~mm}$ de chuva; $\mathrm{B}$ : simulação de $10 \mathrm{~mm}$ de chuva. *Significativo a $5 \%$ de probabilidade pelo teste $\mathrm{F}$.
Rosolem et al. (2003) argumentam que as diferenças na lixiviação de $\mathrm{K}$ das palhas de espécies de cobertura devem estar na dependência da composição do tecido vegetal de cada espécie, que varia de acordo com teores de celulose, lignina e outros, considerando-se também as diferenças morfológicas dos órgãos aéreos das plantas como a pilosidade das folhas. Assim, as espécies que têm mais tecido de colmo em relação às folhas, como no caso do milheto, apresentariam maior retenção do nutriente, pois as células do colmo poderiam estar em um estádio mais avançado de lignificação, dificultando tanto a entrada de água como a saída de K.

$\mathrm{O}$ potencial das espécies estudadas em disponibilizar $\mathrm{K}$ foi determinado, calculando-se a porcentagem do nutriente extraído em relação ao total acumulado no tecido vegetal (Figura 4). Em ambas


Figura 4. Porcentagem de potássio lixiviado em relação ao total acumulado no tecido vegetal da aveia-preta e do milheto. A: simulação de $5 \mathrm{~mm}$ de chuva; B: simulação de $10 \mathrm{~mm}$ de chuva. *Significativo a $5 \%$ de probabilidade pelo teste $\mathrm{F}$. 
as lâminas de chuvas, as porcentagens de $\mathrm{K}$ lixiviado da palha de aveia-preta foram crescentes até $15 \mathrm{DAD}$, diferentemente do milheto, em que o potencial máximo de lixiviação de $\mathrm{K}$ ocorreu aos 9 DAD. Com $5 \mathrm{~mm}$ de chuva, a extração relativa de $\mathrm{K}$ foi semelhante entre as espécies (Figura $4 \mathrm{~A}$ ), evidenciando que as maiores quantidades de $\mathrm{K}$ extraídas da aveia-preta com essa lâmina de chuva (Figura $3 \mathrm{~A}$ ) ocorreram devido ao maior acúmulo desse elemento no tecido vegetal em relação ao milheto (Figura 5). Já com $10 \mathrm{~mm}$ de chuva (Figura 4 B) a aveia-preta apresentou maior potencial em disponibilizar K, pois liberou, aproximadamente, $7 \%$ do $\mathrm{K}$ acumulado no tecido vegetal aos $15 \mathrm{DAD}$, contra 4\% liberados pelo milheto aos 9 DAD.

Resultados semelhantes, encontrados por Calonego et al. (2005), mostram que a extração do K pela chuva simulada sobre as plantas ainda túrgidas, dois dias após a aplicação do herbicida, foi inferior a $1 \%$ do total acumulado nos tecidos da parte aérea vegetal em todas as espécies estudadas. Porém, aos 16 dias, a lixiviação de $\mathrm{K}$ atingiu valores acima de $5 \%$ nas palhas da braquiária, triticale, crotalária-juncea e aveia-preta, e de 4 e $3 \%$ no sorgo-de-guiné e milheto, respectivamente, sem que houvesse decomposição biológica dos restos vegetais.

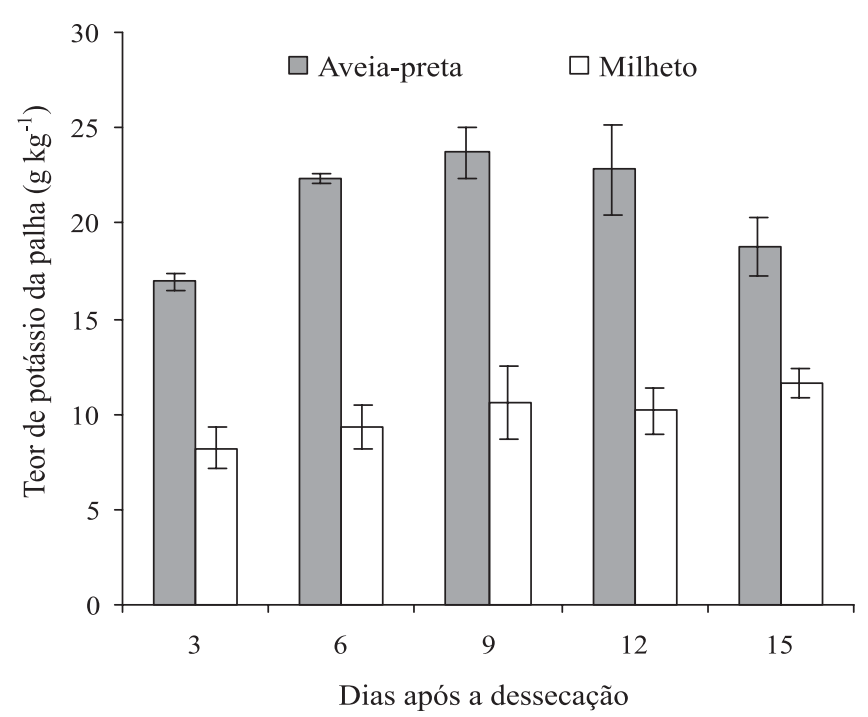

Figura 5. Teor de potássio da palha do milheto e da aveiapreta em diferentes estádios após a dessecação química das plantas. Barras verticais em cada coluna representam os desvios-padrão das médias.
Esses resultados confrontam as observações realizadas por Moraes \& Arens (1969) e Rosolem (1997), que destacaram a facilidade de liberação de $\mathrm{K}$, mas concordam em que a liberação depende, entre outros fatores, do regime de chuvas. Embora Malavolta (1980) tenha relatado que $80 \%$ do K do tecido seria passível de lavagem, devido ao fato de este elemento se encontrar quase que totalmente na forma solúvel, os resultados mostram que essa lavagem depende também de outros fatores além da chuva. Provavelmente maior liberação do K dependeria da degradação da palha, que não foi considerada neste trabalho. Isto pode ter um importante significado ecológico na reciclagem de nutrientes e na fertilização das camadas superficiais do solo.

Crusciol et al. (2005) notaram, em condições de campo, que o nabo forrageiro disponibilizou $92 \%$ do K acumulado no tecido vegetal, após 53 dias do manejo das plantas. No entanto, os autores não fazem referência às quantidades de chuvas ocorridas no período. Os resultados deste experimento mostram que, além do tempo de exposição, a quantidade de chuva recebida pela palha e o grau de senescência das plantas também são importantes, assim como a espécie vegetal considerada.

Os aproximadamente $11 \mathrm{~kg} \mathrm{ha}^{-1} \mathrm{de} \mathrm{K}$ disponibilizados da palha de aveia-preta aos 15 DAD, com aplicação de $10 \mathrm{~mm}$ de chuva (Figura $3 \mathrm{~B}$ ), representam mais de 20\% da dose recomendada desse nutriente na cultura da soja para teores de $\mathrm{K}$ do solo em torno de $2 \mathrm{mmol}_{\mathrm{c}} \mathrm{dm}^{-3} \mathrm{e}$ produtividade esperada de 3 a 3,5 $\mathrm{t} \mathrm{ha}^{-1}$ de grãos (Raij et al., 1996). Dessa forma, na prática da adubação potássica, é importante que se conheça o histórico de manejo das plantas de cobertura, bem como a precipitação pluvial entre o manejo e a semeadura da cultura subseqüente, uma vez que a quantidade de $\mathrm{K}$ da palha que estará prontamente disponível depende da espécie, da chuva recebida e do grau de senescência das plantas, e pode ser significativa considerando-se doses de adubo normalmente recomendadas.

\section{Conclusões}

1. O estado de hidratação do tecido vegetal influencia a lixiviação de potássio da palha da aveia-preta com as lâminas de 5 e $10 \mathrm{~mm}$ de chuva, e da palha de milheto com a lâmina de $10 \mathrm{~mm}$ de chuva.

2. A água da chuva extrai maior quantidade de potássio da palha de aveia-preta em relação à da palha de milheto, tanto com a lâmina de $5 \mathrm{~mm}$ como de $10 \mathrm{~mm}$, 
e essas diferenças aumentam conforme o maior estado de desidratação do material vegetal.

3. O potencial máximo de disponibilização de potássio da palha de milheto pela água da chuva ocorre com o tecido vegetal apresentando maior umidade em relação à palha de aveia-preta.

\section{Referências}

AHRENS, W.H. Herbicide handbook. 7.ed. Champaingn: Weed Science Society of America, 1994. 352p.

CALONEGO, J.C.; ROSOLEM, C.A.; FOLONI, J.S.S. Lixiviação de potássio da palha de plantas de cobertura em diferentes estádios de senescência após a dessecação química. Revista Brasileira de Ciência do Solo, v.29, p.99-108, 2005.

CRUSCIOL, C.A.C.; COTTICA, R.L.; LIMA, E. do V.; ANDREOTTI, M.; MORO, E.; MARCON, E. Persistência de palhada e liberação de nutrientes do nabo forrageiro no plantio direto. Pesquisa Agropecuária Brasileira, v.40, p.161-168, 2005.

EMBRAPA. Centro Nacional de Pesquisa do Solo. Manual de métodos de análises de solo. Rio de Janeiro: Embrapa-CNPS, 1997. $212 \mathrm{p}$

EMBRAPA. Centro Nacional de Pesquisa de Solos. Sistema brasileiro de classificação de solos. Rio de Janeiro: EmbrapaCNPS, 1999. 412p.

FIORIN, J.E. Plantas recuperadoras de fertilidade do solo. In: Curso sobre aspectos básicos de fertilidade e microbiologia do solo em plantio direto, 3., 1999, Cruz Alta. Resumos de palestras. Passo Fundo: Aldeia Norte, 1999. 92p.

FOLONI, J.S.S.; ROSOLEM, C.A. Potassium balance in soybean grown under no-till. In: International Crop Science Congress, 4., Brisbane, 2004. Proceedings. Brisbane: ICSS, 2004.

KLEPKER, D.; ANGHINONI, I. Características físicas e químicas do solo afetadas por métodos de preparo e modos de adubação. Revista Brasileira de Ciência do Solo, v.19, p.395401, 1995.

MACIEL, C.D. de G. Simulação do caminhamento de herbicidas em diferentes tipos e quantidades de palhas utilizadas no sistema de plantio direto. 2001. 89p. Dissertação (Mestrado) - Universidade Estadual Paulista, Botucatu.
MALAVOLTA, E.A. Elementos de nutrição mineral de plantas. São Paulo: Ceres, 1980. 251p.

MALAVOLTA, E.A.; VITTI, G.C.; OLIVEIRA, S.A. Avaliação do estado nutricional das plantas: princípios e aplicações. Piracicaba: Potafos, 1997. 201p.

MARSCHNER, H. Mineral nutrition of higher plants. London: Academic Press, 1995. 889p.

MORAES, J.A.P.; ARENS, K. Eliminação de potássio pelas folhas em dependência da luz e obscuridade. Ciência Cultural, n.21, 728-370, 1969.

RAIJ, B. van. Fertilidade do solo e adubação. Piracicaba: Potafos, 1991. 343p.

RAIJ, B. van; ANDRADE, J.C.; CANTARELLA, H.; QUAGGIO, J.A. Análise química para avaliação da fertilidade de solos tropicais. Campinas: Instituto Agronômico, 2001. 285p.

RAIJ, B. van; CANTARELLA, H.; QUAGGIO, J.A.; FURLANI, A.M.C. (Ed.). Recomendações de adubação e calagem para o Estado de São Paulo. 2.ed. Campinas: Instituto Agronômico; Fundação IAC, 1996. 285p.

ROSOLEM, C.A. Adubação potássica em semeadura direta. In: Simpósio sobre fertilidade do solo em plantio direto. Anais. Dourados: Embrapa-CPAO, 1997. 12p. (Resumos e Palestras).

ROSOLEM, C.A.; CALONEGO, J.C.; FOLONI, J.S.S. Lixiviação de potássio da palha de coberturas de solo em função da quantidade de chuva recebida. Revista Brasileira de Ciência do Solo, v.27, p.355-362, 2003.

ROSOLEM, C.A.; GARCIA, R.A.; FOLONI, J.S.S.; CALONEGO, J.C. Lixiviação de potássio no solo de acordo com suas doses aplicadas sobre palha de milheto. Revista Brasileira de Ciência do Solo, v.30, p.813-819, $2006 a$.

ROSOLEM, C.A.; SANTOS, F.P. dos; FOLONI, J.S.S.; CALONEGO, J.C. Potássio no solo em conseqüência da adubação sobre a palha de milheto e chuva simulada. Pesquisa Agropecuária Brasileira, v.41, p.1033-1040, 2006b.

SILVA, J.E.; RITCHEY, K.D. Acumulação diferencial de potássio em oxissolos devido à lavagem do nutriente das plantas de milho para o solo. Revista Brasileira de Ciência do Solo, v.6, p.183$188,1982$.

SILVA, M.A. de S. Depósitos de calda de pulverização no solo e em plantas de tiririca (Cyperus rotundus L.) em diferentes condições de aplicação. 2000. 57p. Tese (Doutorado) - Universidade Estadual Paulista, Botucatu.

Recebido em 19 de março de 2007 e aprovado em 3 de julho de 2007 